\title{
Breast Cancer Screening: An Assessment of Awareness, Attitude and Practice among Female Clients Utilizing Breast Imaging Services in South-Western Nigeria
}

\author{
Olufunso Simisola Aduayi ${ }^{1}$, Victor Adovi Aduayi ${ }^{2}$ Caleb Adegbenro ${ }^{3}$ \\ ${ }^{1}$ Department of Radiology, College of Medicine, Ekiti State University, Ado-Ekiti, Nigeria \\ ${ }^{2}$ Department of Epidemiology and Community Health, College of Medicine, Ekiti State University, Ado-Ekiti, Nigeria \\ ${ }^{3}$ Department of Community Health, College of Health Sciences, Obafemi Awolowo University, Ile-Ife, Nigeria
}

Email address:

victoraduayi@yahoo.com (V. A. Aduayi)

\section{To cite this article:}

Olufunso Simisola Aduayi, Victor Adovi Aduayi, Caleb Adegbenro. Breast Cancer Screening: An Assessment of Awareness, Attitude and Practice among Female Clients Utilizing Breast Imaging Services in South-Western Nigeria. Science Journal of Public Health. Vol. 4, No. 3, 2016, pp. 219-223. doi: 10.11648/j.sjph.20160403.19

Received: April 22, 2016; Accepted: May 3, 2016; Published: May 13, 2016

\begin{abstract}
Breast cancer is a leading cause of cancer deaths among women in many parts of the world and screening practices play a vital role in its prevention and early detection. This study sought to assess the level of awareness, determine the attitude and document breast cancer screening practices among respondents. A cross-sectional descriptive survey of 150 respondents was conducted at the Department of Radiology of a tertiary health facility in Ado-Ekiti, Nigeria. The study population consisted of female patients referred for breast imaging. A structured questionnaire was used for data collection. The data was analysed using SPSS version 16, Chicago USA Inc. Respondents presented for breast imaging due to breast related complaints $(75.2 \%)$ as opposed to routine medical screening for breast cancer $(24.8 \%)$. A total of $43(28.7 \%)$ respondents had breast ultrasound scan done previously, 105 (70\%) had practiced breast self examination (BSE) before, while $54(36 \%)$ had clinical breast examination (CBE) done previously. Among those aged 40 years and above ( $\mathrm{n}=67,44.7 \%)$ only $18(26.9 \%)$ had a previous mammographic screening. Overall attitude to BSE was good (56\%) but attitude to CBE was negative (69.3\%). Respondents' occupation was found to have a significant association with attitude towards BSE $(\mathrm{p}=0.001)$. The logistic regression analysis of predictors of awareness of mammography showed that women aged 40 years and above are more likely to be aware of mammography as a screening tool for breast cancer $(\mathrm{OR}=3.05, \mathrm{P}=0.012 ; 95 \% \mathrm{CI} 1.28-7.27)$. There is a need for increased awareness and adoption of breast cancer screening practices in our environment in order to engender a reduction in breast cancer morbidity and mortality.
\end{abstract}

Keywords: Breast Cancer, Screening Methods, Imaging Services

\section{Introduction}

Breast cancer is the most common cancer among women both in developed and developing countries, comprising $23 \%$ of all female cancers. [1] Globally, one million new breast cancer cases are diagnosed each year [2]. Breast cancer screening methods have been found to help with early detection of breast lesions and the methods include breast self-examination (BSE), clinical breast examination (CBE) and radiological imaging of the breast using low dose $\mathrm{x}$-ray in mammography [3]. Breast cancer screening can also involve Ultrasonography and Magnetic Resonance Imaging
(MRI). Breast cancer has continually caused significant morbidity and mortality among women in middle and low income countries owing to a delay in seeking health care for breast related complaints. In developing countries, late presentation by breast cancer patients has frequently been reported. [4] Delay in seeking treatment is further compounded by ignorance and misconceptions about the disease. When women present to health facilities late and at advanced stages of the disease, little or no benefit is derived from any form of therapy. [5, 6] In contrast, breast cancer patients from developed nations present earlier, and a significant proportion are detected by screening 
mammography. The aim of the study is to assess the level of awareness, determine the attitude and document breast cancer screening practices among females presenting for breast imaging services at our health care facility.

\section{Subjects and Methods}

This is a hospital based cross sectional descriptive study conducted at the Radiology department of Ekiti State University Teaching Hospital (EKSUTH), Ado-Ekiti; a city in southwest Nigeria. Ethical approval for the study was obtained from the institution's ethics and research committee. The instrument for data collection was a semi-structured questionnaire which contained relevant questions on attitude and practice of the study participants towards breast cancer screening practices. All consenting clients aged 18 years and above, presenting for breast imaging were recruited culminating in the selection of 150 female clients over the study period of one year. Clients who were referred to the department for other radiological investigations were excluded from the study. The raw data was entered into a computer spread sheet and analysed using SPSS version 16, Chicago USA Inc. Descriptive, bivariate and multivariate analyses were carried out as appropriate. Socio-demographic and other relevant variables (age, occupation, education, marital status etc) were presented in frequencies and proportions. Inferential statistics, chi-square test was used to test for associations between categorical variables. Multivariate analyses (binary logistic regression) were employed to identify independent and significant factors and to correct for confounding variables that may influence awareness of mammography.

\section{Results}

All the respondents were females, age range 18-70 years with a mean age of $37.39 \pm 13.2$ years. A higher proportion of respondents $(78.7 \%)$ had at tertiary level of education. Majority of respondents $(62.7 \%)$ were married. With respect to respondent's religion, they were predominantly Christians (96.0\%) (Table 1) The most common clinical indication for breast imaging was breast pain $(41.6 \%)$, followed by routine medical screening for breast cancer $(24.8 \%)$. (Figure 1)

About $83.3 \%$ of respondents had heard of BSE previously while only $41.3 \%$ of the respondents were aware of mammography as a breast cancer screening tool. The most common source of information on mammography was the print and electronic media $(n=34,56.7 \%)$, followed by information from doctors $(n=32,53.3 \%)$. Other sources of information $(n=31,50.6 \%)$ on mammography included women organizations, religious groups, family members and friends. The most common source of information on BSE was from doctors, nurses and other health workers $(n=87$, $70.1 \%)$, followed by the print and electronic media $(n=46$, $37.1 \%)$. Other sources of information $(n=26,21.0 \%)$ on BSE included friends and family members.

A total of $43(28.7 \%)$ respondents out of the entire study population had breast ultrasound scan done in the past, 105 $(70 \%)$ of respondents had done BSE previously while $54(36 \%)$ respondents had clinical breast examination (CBE) done at a health facility previously. Among the 67 respondents aged 40 years and above in the study population only $18(26.9 \%)$ had a previous mammographic screening.

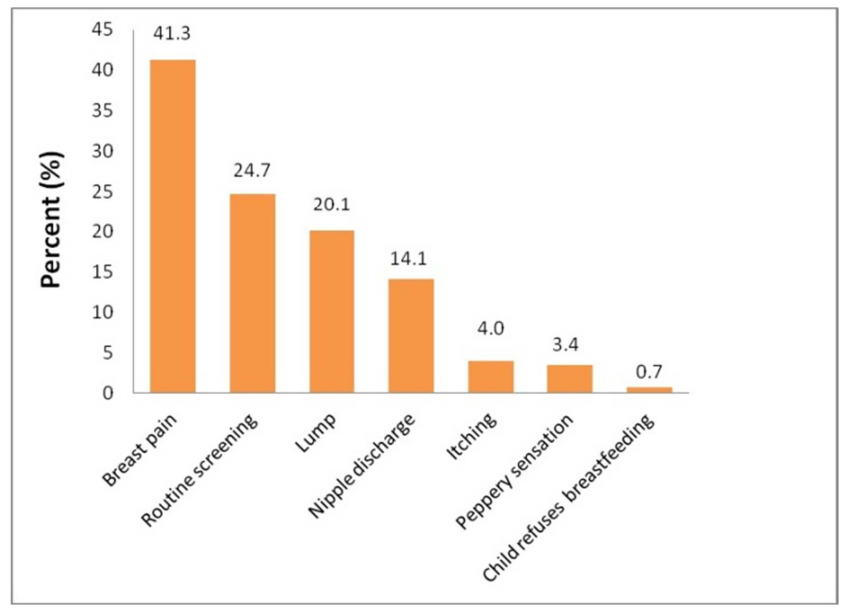

Figure 1. Reasons why participants presented for breast imaging.

Table 1. Sociodemographic characteristics.

\begin{tabular}{lll}
\hline Background Characteristics & N & \% \\
\hline Age (years) & & \\
$<20$ & 15 & 10.0 \\
$20-29$ & 33 & 22.0 \\
$30-39$ & 34 & 22.7 \\
$40-49$ & 40 & 26.7 \\
$\geq 50$ & 28 & 18.7 \\
Education & & \\
Tertiary & 118 & 78.7 \\
Secondary & 26 & 17.3 \\
Primary & 6 & 4.0 \\
Marital Status & & \\
Single & 53 & 35.3 \\
Married & 94 & 62.7 \\
Divorced/Separated & 2 & 1.3 \\
Widow & 1 & 0.7 \\
Occupation & & \\
Professional & 48 & 32.0 \\
Skilled worker & 31 & 20.6 \\
Unskilled worker & 21 & 14.0 \\
Others (Student, retired, unemployed) & 50 & 33.4 \\
Religion & & \\
Christianity & 144 & 96.0 \\
Islam & 6 & 4.0 \\
\hline
\end{tabular}

Out of 105 respondents that had done BSE in the past, 44 $(41.9 \%)$ which is a higher proportion believe that it should be done once a week. Regarding the ideal time in a month when BSE is best done, $29.0 \%$ of respondents do not know while another $29.0 \%$ think it can be done anytime. Among the respondents who did not practise BSE, majority (51.1\%) gave reasons of not knowing how to do it. (Table 2) The overall attitude to BSE was positive $(56.0 \%)$.

Among the 54(36\%) respondents that had a previous CBE, $35(64.8 \%)$ had it within the year, $8(14.8 \%)$ two years ago and $11(20.4 \%)$ about 3 or more years ago. About 44(29.3\%) respondents never had a $\mathrm{CBE}$ done because they felt they had 
no breast problem while $52(34.7 \%)$ were not aware of CBE. The overall attitude to CBE was negative (69.3\%). A summary of the overall level of awareness on mammography and the attitude to BSE and CBE is shown in Table 2.

Table 2. Attitude and practice towards breast cancer screening methods.

\begin{tabular}{lll}
\hline & Frequency (N) & Percentage (\%) \\
\hline How often is BSE done & & \\
Once a week & 44 & 42.0 \\
Once a month & 31 & 29.5 \\
1-6 times a year & 30 & 28.5 \\
Appropriate time for BSE & & \\
some days before menses & 14 & 9.3 \\
Some days after menses & 32 & 21.3 \\
During menses & 26 & 17.3 \\
Any time & 39 & 29.0 \\
I don't know & 39 & 29.0 \\
Reasons for not doing BSE & & \\
I don't know how to do it & 23 & 51.1 \\
I don't have a breast problem & 13 & 28.9 \\
I don't think I should & 1 & 2.2 \\
I Don't think I will find anything & 3 & 6.7 \\
Laziness/carelessness & 3 & 6.7 \\
I am not pregnant & 2 & 4.4 \\
Awareness about mammography & & \\
Aware & 62 & 41.3 \\
Unaware & 88 & 58.7 \\
Attitude to BSE & & \\
Positive & 84 & 56.0 \\
Negative & 66 & 44.0 \\
Attitude to CBE & & 30.7 \\
Positive & 46 & 69.3 \\
Negative & 104 & \\
\hline
\end{tabular}

The relationship between socio-demographic characteristics and Attitude to BSE (Table 3) was explored and it was observed that women aged 50 years and above had a positive attitude towards BSE (64.1\%) followed by women aged 20-29 years (60.6\%). Most respondents who had a positive attitude towards BSE had the highest level of education (59.3\%). Respondents occupation was found to have a significant association with attitude towards BSE $(\mathrm{p}=0.001)$.

Table 3. Relationship between socio-demographic characteristics and Attitude to Breast Self-Examination.

\begin{tabular}{llllllll}
\hline \multicolumn{5}{c}{ Attitude to BSE } \\
& $\begin{array}{l}\text { Negative } \\
\text { attitude }\end{array}$ & $\begin{array}{l}\text { Positive } \\
\text { attitude }\end{array}$ & & \\
\hline Background characteristics & N & $\%$ & N & $\%$ & $\chi^{2}$ & P \\
\hline Age (years) & 8 & 53.3 & 7 & 46.7 & 2.734 & 0.603 \\
$<20$ & 13 & 39.4 & 20 & 60.6 & & \\
$20-29$ & 18 & 52.9 & 16 & 47.1 & & \\
$30-39$ & 17 & 42.5 & 23 & 57.5 & & \\
$40-49$ & 10 & 35.7 & 18 & 64.3 & & \\
$>=50$ & & & & & & \\
Education & 48 & 40.7 & 70 & 59.3 & 2.578 & 0.275 \\
Tertiary & 15 & 57.7 & 11 & 42.3 & & \\
Secondary & 3 & 50.0 & 3 & 50.0 & & \\
$\begin{array}{l}\text { Primary } \\
\text { Marital Status }\end{array}$ & 25 & 47.2 & 28 & 52.8 & 0.334 & 0.563 \\
Never married (Single) & 41 & 42.3 & 56 & 57.7 & & \\
Ever Married(Married, & & & & & & \\
separated, divorced, widow) & & & & & & & \\
\hline
\end{tabular}

\begin{tabular}{llllllll}
\hline \multicolumn{5}{c}{ Attitude to BSE } & & \\
\hline & $\begin{array}{l}\text { Negative } \\
\text { attitude }\end{array}$ & $\begin{array}{l}\text { Positive } \\
\text { attitude }\end{array}$ & \\
\hline Background characteristics & N & $\%$ & N & $\%$ & $\chi^{2}$ & P \\
\hline Occupation & 11 & 22.9 & 37 & 77.1 & 15.454 & $0.001^{*}$ \\
Professional & 20 & 64.5 & 11 & 35.5 & & \\
Skilled worker & 12 & 57.1 & 9 & 42.9 & & \\
Unskilled worker & 23 & 46.0 & 27 & 54.0 & & \\
Others (Student, retired, & & & & & & \\
unemployed) & 63 & 43.8 & 81 & 56.3 & $0.091_{\mathrm{E}}$ & 0.763 \\
Religion & 3 & 50.0 & 3 & 50.0 & & \\
Christianity & Islam & & & & & \\
\hline
\end{tabular}

$\chi^{2}=$ Pearson Chi-square, ${ }^{*}$ Statistically significant at $\mathrm{p}$ value $<0.05 * *$ Statistically significant at $\mathrm{p}$ value $<0.001$

The relationship between socio-demographic characteristics and Attitude towards CBE was explored and it was observed that women aged 50 years and above had the most positive attitude (39.3\%) towards CBE. Most respondents who had a positive attitude towards CBE had their highest level of education being secondary (34.6\%). (Table 4)

Table 4. Relationship between socio-demographic characteristics and Attitude to Clinical Breast Examination.

\begin{tabular}{|c|c|c|c|c|c|c|}
\hline \multirow[b]{3}{*}{ Background characteristics } & \multicolumn{5}{|c|}{ Attitude to CBE } & \multirow[b]{3}{*}{$\mathbf{P}$} \\
\hline & \multicolumn{2}{|c|}{$\begin{array}{l}\text { Negative } \\
\text { attitude }\end{array}$} & \multicolumn{3}{|c|}{$\begin{array}{l}\text { Positive } \\
\text { attitude }\end{array}$} & \\
\hline & $\mathbf{N}$ & $\%$ & $\mathbf{N}$ & $\%$ & $\chi^{2}$ & \\
\hline \multicolumn{7}{|l|}{ Age (years) } \\
\hline$<20$ & 12 & 80.0 & 3 & 20.0 & 2.951 & 0.566 \\
\hline $20-29$ & 23 & 69.7 & 10 & 30.3 & & \\
\hline $30-39$ & 26 & 76.5 & 8 & 23.5 & & \\
\hline $40-49$ & 26 & 65.0 & 14 & 35.0 & & \\
\hline$>=50$ & 17 & 60.7 & 11 & 39.3 & & \\
\hline \multicolumn{7}{|l|}{ Education } \\
\hline Tertiary & 82 & 69.5 & 36 & 30.5 & 0.808 & 0.689 \\
\hline Secondary & 17 & 65.4 & 9 & 34.6 & & \\
\hline Primary & 5 & 83.3 & 1 & 16.7 & & \\
\hline \multicolumn{7}{|l|}{ Marital Status } \\
\hline Never married (Single) & 40 & 75.5 & 13 & 24.5 & 1.452 & 0.228 \\
\hline $\begin{array}{l}\text { Ever Married(Married, } \\
\text { separated, divorced, widow) }\end{array}$ & 64 & 66.0 & 33 & 34.0 & & \\
\hline \multicolumn{7}{|l|}{ Occupation } \\
\hline Professional & 34 & 70.8 & 14 & 29.2 & 2.207 & 0.531 \\
\hline Skilled worker & 18 & 58.1 & 13 & 41.9 & & \\
\hline Unskilled worker & 15 & 71.4 & 6 & 28.6 & & \\
\hline $\begin{array}{l}\text { Others (Student, retired, } \\
\text { unemployed) }\end{array}$ & 37 & 74.0 & 13 & 26.0 & & \\
\hline \multicolumn{7}{|l|}{ Religion } \\
\hline Christianity & 101 & 70.1 & 43 & 29.9 & 1.016 & 0.296 \\
\hline Islam & 3 & 50.0 & 3 & 50.0 & & \\
\hline
\end{tabular}

$\chi^{2}=$ Pearson Chi-square, ${ }^{*}$ Statistically significant at $\mathrm{p}$ value $<0.05 * *$ Statistically significant at $\mathrm{p}$ value $<0.001$

The logistic regression analysis of predictors of awareness of mammography (Table 5) shows that, women older than 40 years are more likely to be aware of mammography as a screening tool for breast cancer $(\mathrm{OR}=3.05, \mathrm{P}=0.012 ; 95 \% \mathrm{CI}$ 1.28-7.27). 
Table 5. Multivariate analysis of predictors of awareness about mammography.

\begin{tabular}{|c|c|c|c|}
\hline \multirow[b]{2}{*}{ Background characteristics } & \multicolumn{3}{|c|}{ Awareness on Mammography } \\
\hline & B & $\begin{array}{l}\text { Adjusted OR } \\
(95 \% \text { C.I) }\end{array}$ & $\mathbf{p}$ \\
\hline \multicolumn{4}{|l|}{ Age (years) } \\
\hline$<40$ & - & - & \\
\hline$>=40$ & 1.11 & $3.05 *(1.28-7.27)$ & $0.012 *$ \\
\hline \multicolumn{4}{|l|}{ Occupation } \\
\hline Professional & - & - & \\
\hline Skilled worker & -0.99 & $0.37(0.14-1.03)$ & 0.056 \\
\hline Unskilled worker & -0.78 & $0.46(0.12-1.77)$ & 0.258 \\
\hline $\begin{array}{l}\text { Others (students, retired, } \\
\text { unemployed) }\end{array}$ & -1.03 & $0.36 *(0.14-0.95)$ & 0.039 \\
\hline \multicolumn{4}{|l|}{ Education } \\
\hline Tertiary & - & - & - \\
\hline Secondary & -0.85 & $0.43(0.13-1.42)$ & 0.165 \\
\hline Primary & -1.87 & $0.15(0.02-1.51)$ & 0.108 \\
\hline \multicolumn{4}{|l|}{ Marital Status } \\
\hline Never married (Single) & - & - & \\
\hline Ever Married (others) & 0.51 & $1.66(0.66-4.19)$ & 0.286 \\
\hline \multicolumn{4}{|l|}{ Religion } \\
\hline Christianity & - & - & \\
\hline Islam & -1.46 & $0.23(0.02-2.51)$ & 0.229 \\
\hline
\end{tabular}

*Statistically significant at $\mathrm{p}$ value $<0.05 * *$ Statistically significant at $\mathrm{p}$ value $<0.001$

\section{Discussion}

Breast cancer remains the commonest malignancy affecting women as reported from population based cancer registries in Nigeria. [7] The need for breast cancer awareness and regular screening in order to facilitate early detection and treatment is key to reducing the morbidity and mortality attributed to breast cancer. [8] Adoption of breast cancer screening methods is generally poor in the developing countries and this is not unconnected with inadequate knowledge about breast cancer. [9, 10] Majority of the respondents $(75.2 \%)$ in our study came for breast imaging as a result of a breast related complaint while only $24.8 \%$ presented for routine breast cancer screening. This reinforces the fact that the women in our environment are yet to embrace breast screening practices but only see a need to visit the hospital whenever there are complaints. About $70 \%$ of the respondents in this study claim to practice BSE. A study conducted by Akinola et al in Nigeria showed that $67.6 \%$ of the respondents practiced BSE [11] but in contrast to findings by Adegbenro et al and Okobia et al which revealed in separate studies that about $30 \%$ of women ever practiced BSE [5, 12]. A survey of women in Iran also revealed that BSE was practiced by only $17 \%$ of the respondents. [13] BSE is an inexpensive and simple method which women can be taught in order to ensure that it is done the appropriate way and at the appropriate time. While it may help to create an awareness about breast cancer, there is no clear evidence that performing routine BSE aids in the early detection of breast cancer or that it reduces breast cancerrelated mortality. [13]

Recent estimates suggest that $\mathrm{CBE}$ has a sensitivity of about $54 \%$ and a specificity of about $94 \%$. However, it has been shown that clinical breast examination may only detect about $60 \%$ of breast cancers that are detected by mammography. [13] This study showed that $36 \%$ of the respondents had ever had a $\mathrm{CBE}$ done and overall attitude to CBE was negative (69.3\%). A feeling that they had no problems with their breast coupled with lack of awareness about $\mathrm{CBE}$ constituted major reasons why the respondents were not undergoing $\mathrm{CBE}$. This underscores the need for client health education in health facilities in order to engender voluntary participation in CBE in our environment.

Mammography is the gold standard for breast cancer screening. [14] Women aged 40 and above are eligible for routine mammographic screening, however dense breasts reduces the sensitivity of the study. Evidence supporting the usefulness of mammographic screening is strongest for women between 50 and 69 years of age. [15] In women with dense breasts additional imaging using ultrasonography is often done. Ultrasonography is also utilized for breast imaging in the female clients less than 40 years of age. MRI is not readily available in resource poor settings and this limits its use for breast imaging in the developing world. Notwithstanding, the contribution of breast self-examination, clinical breast examination, ultrasonography and even mammography to reduce the number of deaths from cancer is currently a source of controversy. [16] However in developing countries were late presentations is rampant, promoting the practice of breast self-examination, clinical breast examination and regular mammography screening remains advantageous. Mammography is gradually becoming more available in health care facilities across Nigeria. The findings from this study showed that awareness of mammography among women was low, as only $41.3 \%$ of the respondents had ever heard of mammography. This is in line with findings from other studies. [11, 17] The multivariate analysis showed that women aged 40 years and above were more likely to be aware of mammography in this study. This may be linked to the fact that this group of women are also the ones eligible for routine mammographic screening.

Socio-demographic characteristics such as the level of education, $[5,18]$ has been identified as influencing the level of knowledge and utilization of screening services in general with higher levels of awareness and utilization of screening services displayed among the educated and those with high socioeconomic class. Respondents' occupation was found to have a significant association with attitude towards BSE $(p=0.001)$. Also the respondents with a tertiary level of education constituted a majority of those had positive attitude to BSE. This study revealed that the level of education of a woman is a key factor influencing adoption of breast cancer screening practices. Women who had a higher level of education, were more likely to practice BSE and easily utilize other screening methods if the need arises. This is contrary to a study by Sensiba et al that educated women often forget to practise BSE. [19]

Information on BSE was mostly obtained from doctors, nurses and other health workers in this research. Healthcare providers not only play an important role in treating patients 
but are also responsible for improving patient behaviours and screening, as yearly mammography and clinical breast exam is the single most important step that clinicians can take to reduce suffering and death from breast cancer [7]. A greater proportion of respondent got information on mammography from the print and electronic media. This shows the impact of the media on information dissemination. Strategies such as 'Enter-Educate' can be incorporated in form jingles, songs, playlets and write ups to arouse the interest of listeners, viewers, and readers while passing the educative information on breast cancer screening methods. [20]

\section{Conclusion}

Lack of awareness about breast cancer screening methods, poor attitude to preventive measures and unfavourable socioeconomic situation will have a negative impact on the adoption of breast cancer screening practices among women in any environment. A behavioural change that stimulates a positive attitude to breast cancer screening practices will ultimately translate to a much desired reduction in the morbidity and mortality related to this dreaded disease in developing countries.

\section{References}

[1] Ferlay J, Shin HR, Bray F, Forman D, Mathers C, Parkin DM. Estimates of worldwide burden of cancer in 2008: GLOBOCAN 2008. International Journal of Cancer. 2010; 127(12): 2893-917.

[2] Yeole BB, Kurkure A. An epidemiological assessment of increasing incidence and trends in breast cancer in Mumbai and other sites in India, during the last two decades. Asian Pacific Journal of Cancer Prevention. 2003; 4(1): 51-6.

[3] Broeders M, Verbeek A. Breast cancer epidemiology and risk factors. The quarterly journal of nuclear medicine: official publication of the Italian Association of Nuclear Medicine (AIMN)[and] the International Association of Radiopharmacology (IAR). 1997; 41(3): 179-88.

[4] Jedy-Agba E, Curado MP, Ogunbiyi O, Oga E, Fabowale T, Igbinoba F, et al. Cancer incidence in Nigeria: A report from population-based cancer registries. Cancer epidemiology. 2012.

[5] Okobia MN, Bunker CH, Okonofua FE, Osime U. Knowledge, attitude and practice of Nigerian women towards breast cancer: a cross-sectional study. World journal of surgical oncology. 2006; 4(1): 1 .

[6] Aduayi VA, Onayade AA, Aduayi OS, Ijadunola MY. Willingness to accept preventive bilateral mastectomy among women in rural and urban communities in South-Western Nigeria. International Journal of Community Medicine and Public Health. 2015; 2(2): 86-93.

[7] Jedy-Agba E, Curado MP, Ogunbiyi O, Oga E, Fabowale T, Igbinoba F, et al. Cancer incidence in Nigeria: a report from population-based cancer registries. Cancer epidemiology. 2012; 36(5): e271-e8.

[8] Aduayi VA, Aduayi OS, Onayade A, Esimai OA. A Community Based Rural-Urban Comparison of Knowledge and Perception of Women towards Breast Cancer in South Western Nigeria. International Journal of Health Sciences and Research (IJHSR). 2016; 6(4): 26-32.

[9] Oluwatosin OA, Oladepo O. Knowledge of breast cancer and its early detection measures among rural women in Akinyele local government area, Ibadan, Nigeria. BMC cancer. 2006; 6(1): 271 .

[10] Oluwatosin OA. Rural Women's Perception of Breast Cancer and its Early-detection Measures in Ibadan, Nigeria. Cancer Nursing. 2006;29(6):461.

[11] Akinola R, Wright K, Osunfidiya O, Orogbemi O, Akinola O. Mammography and mammographic screening: are female patients at a teaching hospital in Lagos, Nigeria, aware of these procedures? Diagnostic and Interventional Radiology. 2011; 17(2): 125 .

[12] Adegbenro C, Ajala A, Ajayi O, Ajayi T, Ajayi O, Ajewole A, et al. Awareness of Breast Cancer and Practice of Breast SelfExamination among Rural Women in Ife-North Local Government Area, Osun State, South-West Nigeria. Journal of Community Medicine and Primary Health Care. 2015; 26(1): 76-87.

[13] Montazeri A, Vahdaninia M, Harirchi I, Harirchi AM, Sajadian A, Khaleghi F, et al. Breast cancer in Iran: need for greater women awareness of warning signs and effective screening methods. Asia Pacific Family Medicine. 2008; $7(1): 1$.

[14] Pinsky RW, Helvie MA. Role of Screening Mammography in Early Detection/Outcome of Breast Cancer. Ductal Carcinoma In Situ and Microinvasive/Borderline Breast Cancer: Springer; 2015. p. 13-26.

[15] Fletcher SW, Elmore JG. Mammographic screening for breast cancer. New England Journal of Medicine. 2003; 348(17): 1672-80.

[16] Kaniklidis C, Foundation NSBC. Beyond the mammography debate: a moderate perspective. Current Oncology. 2015; 22(3): 220 .

[17] Obajimi MO, Ajayi IO, Oluwasola AO, Adedokun BO, Adeniji-Sofoluwe AT, Mosuro OA, et al. Level of awareness of mammography among women attending outpatient clinics in a teaching hospital in Ibadan, South-West Nigeria. BMC public health. 2013; 13(1): 1 .

[18] Ojikutu R, Adetifa F. Psycho-Social Analysis of Breast Cancer Awareness in Lagos State, Nigeria. International Journal of Academic Research. 2009; 1(2).

[19] Sensiba ME, Stewart DS, editors. Relationship of perceived barriers to breast self-examination in women of varying ages and levels of education. Oncology nursing forum; 1995.

[20] Coleman P. The enter-educate approach for promoting social change. Journal of Development Communication. 2000; 11(1): 75-81. 